See Article page 47

\section{Commentary: Total endoscopic heart surgery: For the few not yet for the many}

\author{
Daniel Paul Fudulu, PhD, and \\ Gianni Davide Angelini, MD
}

In their article, Fukomoto and colleagues ${ }^{1}$ describe the use of a total 3-D endoscopic surgery approach in a young patient with an aorto-right ventricular fistula due to ruptured sinus of Valsalva aneurysm. The case report is presented with clarity and complemented by high-quality perioperative images and an excellent video of the technique. Clearly, the authors are slick in minimally invasive techniques, particularly in totally endoscopic cardiac surgery. However, as alluded to in their work, their sound technique comes from a high volume of totally endoscopic surgical cases performed in their unit. Although this is an attractive technique, it should be performed in a unit with substantial expertise in this type of surgery, and patient safety should always remain the surgeon's focus. Patient selection is also essential; young, straightforward patients with an excellent physiological reserve are likely the right candidates for this approach, especially during the surgeon's learning curve.

A key outcome determinant of minimally invasive cardiac surgery is the establishment of adequate cardioprotection. ${ }^{2}$ Fukomoto and colleagues show how they manage to achieve a well-arrested heart with the use of selective antegrade cardioplegia after achieving hypothermia and ventricular fibrillation using femoral cardiopulmonary bypass.

This technique is not limited to congenital fistulae but also could be applied to iatrogenic, acquired fistulae, for

From the Bristol Heart Institute, Bristol University, Bristol, United Kingdom. Disclosures: The authors reported no conflicts of interest.

The Journal policy requires editors and reviewers to disclose conflicts of interest and to decline handling or reviewing manuscripts for which they may have a conflict of interest. The editors and reviewers of this article have no conflicts of interest.

Received for publication June 2, 2020; revisions received June 2, 2020; accepted for publication June 6, 2020; available ahead of print June 15, 2020.

Address for reprints: Gianni Davide Angelini, MD, Bristol Heart Institute, Bristol

University, Bristol Royal Infirmary, Bristol BS28HW, United Kingdom (E-mail:

g.d.angelini@bristol.ac.uk).

JTCVS Techniques 2020;3:50-1

2666-2507

Copyright (c) 2020 The Authors. Published by Elsevier Inc. on behalf of The American Association for Thoracic Surgery. This is an open access article under the CC BY-NCND license (http://creativecommons.org/licenses/by-nc-nd/4.0/).

https://doi.org/10.1016/j.xjtc.2020.06.009
Check for updates

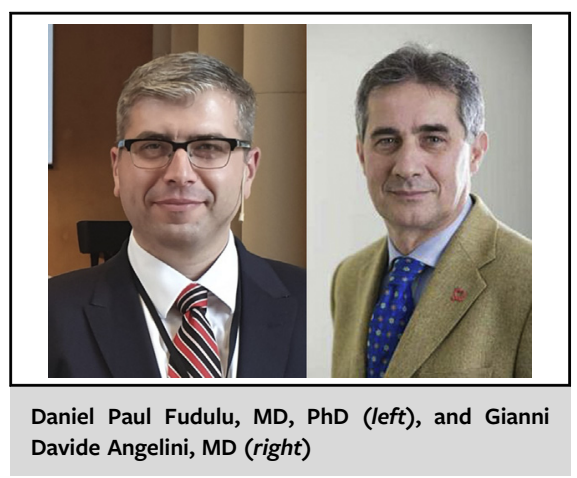

CENTRAL MESSAGE

A total endoscopic approach to aorto-right ventricular fistula

repair is a valuable technique in

the right hands for the right patients.

example, right aorto-ventricular fistula after transcatheter aortic valve replacement, a rare occurrence. ${ }^{3}$ In the context of the increasing volume of transcatheter aortic valve replacements, this approach could prove useful for dealing with such complications when percutaneous approaches are not possible.

As depicted in the video, visualization of the anatomy is sometimes better than with the naked eye, and use of the 3-D vision provides excellent spatial perception for the operator and is superior to $2-\mathrm{D}$ vision systems. ${ }^{4}$ As with any video-assisted procedure, the surgeon can share the video monitor with the rest of the team and record the procedure, a basis for excellent teaching and training in surgery.

Putting this case report into perspective, it provides a testimony as to how much minimally invasive cardiac surgery has expanded. This progress would not have been possible without enthusiastic surgeons embracing new, innovative techniques. Nevertheless, conventional cardiac surgery outcomes should always be the benchmark against which minimally invasive procedures should be measured. Although the debate about the effect on hard endpoints of open cardiac surgery versus minimally invasive cardiac surgery is ongoing, it is evident that such procedures are demanded by patients and are associated with increased patient satisfaction. The future direction of cardiac surgery is toward more endoscopic surgery, accelerated by the rapid advancements of robotic science. Likely more fascinating is the 
potential application of artificial intelligence that will likely enable robots to learn and make predictions from the patterns they learn from thousands of surgeons worldwide, thereby making surgery safer. ${ }^{5}$

\section{References}

1. Fukumoto Y, Hosoba S, Goto Y, Ito T. Totally 3D-endoscopic patch closure of aorto-right ventricular fistula. J Thorac Cardiovasc Surg Tech. 2020;3:47-9.
2. Garbade J, Davierwala P, Seeburger J, Pfannmeuller B, Misfeld M Borger BA, et al. Myocardial protection during minimally invasive mitral valve surgery: strategies and cardioplegic solutions. Ann Cardiothorac Surg. 2013;2:803-8.

3. Shakoor MT, Islam AM, Ayub S. Acquired aorto-right ventricular fistula following transcatheter aortic valve replacement. Case Rep Cardiol. 2015;2015:1-3.

4. Van Bergen P, Kunert W, Bessell J, Buess GF. Comparative study of twodimensional and three-dimensional vision systems for minimally invasive surgery. Surg Endosc. 1998;12:948-54.

5. Hashimoto DA, Rosman G, Rus D, Meireles OR. Artificial intelligence in surgery: promises and perils. Ann Surg. 2018;268:70-6. 